\title{
Del conflicto social a la contienda política en Marmato, Caldas. Un análisis desde las orientaciones colectivas $^{1}$
}

\author{
From social conflict to political contest in Marmato, \\ Caldas. An analysis based on collective orientations
}

\section{Do conflito social à disputa política em Marmato, Caldas. Uma análise das orientações coletivas}

\section{Eduardo Martínez Torres ${ }^{2}$}

Investigador Colectivo de estudios poscoloniales/decolianles en/de América Latina COPAL. Universidad Nacional de Colombia. Facultad de Derecho y Ciencias políticas y sociales

emartineztor@uan.edu.co

Recibido: 11-07-16 Aprobado: 02-11-17

1 Este artículo se fundamenta en la tesis para optar al título de Máster en Ciencias Políticas. FLACSO-Ecuador 2012-2014: "Conflicto social, orientaciones colectivas y contienda política bajo proyectos mineros a gran escala. Comparación de casos: Ecuador y Colombia". Las entrevistas para esta investigación se realizaron entre marzo y mayo de 2014 en el municipio de Marmato y la ciudad de Manizales en el departamento de Caldas.

2 Máster en Ciencias Políticas. 


\title{
Resumen
}

Este artículo tiene por objetivo explicar la dinámica y el proceso del conflicto en Marmato, Caldas (2007-2012), entre actores locales y foráneos institucionales, a partir de los procesos de orientación, acciones, estrategias, interacción y recepción en dinámicas locales y regionales. Se plantean las siguientes preguntas: ¿Cómo interpretan y construyen actores y organizaciones una situación conflictiva? ¿Cómo los actores implicados disputan sus intereses y buscan solidaridad y legitimidad de amplios sectores de la sociedad? La metodología consistió en una revisión de caso a partir de una serie de entrevistas a líderes locales y estudiantiles, revisión de comunicados escritos, videos y páginas virtuales, junto con revisión de literatura que permitió una reconstrucción del caso a profundidad. Se concluyó que el carácter endógeno en la conformación de la lucha social, los conflictos que anteceden al conflicto megaminero y el papel que desempeñarían sectores externos serán fundamentales para construir una dinámica articulada alrededor de unas condiciones de vida propias que actores locales tejieron alrededor de la pequeña minería tradicional.

Palabras clave: minería; conflicto social; movimientos de protesta; sociología política.

\begin{abstract}
This paper is aimed to explain the dynamics and the social conflict process through the processes of orientation, actions, strategies, interaction and reception in local and regional dynamics; which are considered to explain the dynamics of the process of social conflict in Marmato, Caldas (2007-2012). The following questions are posed: How do actors and organizations interpret and construct a conflictive situation? How do the actors involved dispute their interests and seek solidarity and legitimacy from broad sectors of society? The methodology consisted of a case study based on a series of interviews with local leaders and students, review of written statements, videos and virtual pages, along with a literature review that allowed an in-depth reconstruction of the case. It was concluded that the endogenous character of the social struggle, added to the conflicts that precede the mega mining conflict, and the role played by external sectors, it will be fundamental to build an articulated dynamic around specific living conditions that local actors created around traditional small-scale mining.
\end{abstract}

Keywords: mining; social conflict; protest movements; political sociology.

\section{Resumo}

Este trabalho pretende explicar a dinâmica e o processo de conflito em Marmato-Caldas (2007-2012) entre atores locais, estrangeiros e institucionais, com base nos processos de orientação, nas ações-estratégias e na interação-recepção em dinâmicas locais-regionais. Surgem as seguintes questões: como atores e organizações interpretam e constroem uma situação de conflito? Como os atores envolvidos contestam seus interesses e buscam solidariedade e legitimidade de amplos setores da sociedade? A metodologia foi uma indagação de caso de uma série de entrevistas com líderes locais, estudantes, revisão de comunicados escritos, vídeos e páginas virtuais, além de uma revisão da literatura que permitiu uma reconstrução de casos em profundidade. Concluiu-se que o caráter endógeno da luta social, juntamente com os conflitos que precedem à megamineração e o papel desempenhado pelos setores externos, será fundamental para construir uma dinâmica articulada em torno das condições de vida típicas de atores locais, envolvidos na mineração tradicional em pequena escala.

Palavras-chave: mineração; conflito social; movimentos de protesto; sociologia política. 


\section{Introducción}

Los territorios y sus recursos -materiales y simbólicos- se han constituido en uno de los objetos principales de conflictos públicos por posicionar usos, prácticas y significados. El presente artículo busca resaltar la multiplicidad de actores e intereses que dan forma y componen el conflicto social y la contienda política que se conformó en el proyecto minero de Marmato, en Caldas, Colombia, entre 2007 y 2012. Se observó el proceso organizativo y de orientación colectiva, que permitió estructurar distintas formas de lucha social y política. En el proceso de orientación se observan actores institucionales, no institucionales y su interacción y recepción en dinámicas locales y regionales. Se resaltará la distinción entre conflicto social y contienda política, esta última resultado del proceso de interacción de actores e intereses y su disputa en el juego político.

Primero, se describe el proceso de surgimiento y desarrollo de la dinámica organizativa y conflictiva, centrándose en el proceso de orientación, el uso de discursos y lenguajes comunes (qué dicen y cómo lo dicen). Segundo, analizar las estrategias de orientación de lo que estaría en juego (cómo lo difunden), y su relación en la búsqueda de apoyo social y legitimidad en un proceso de contienda política. Tercero, se expondrán las formas en que el gobierno central despliega estrategias dependiendo del carácter y trayectoria del conflicto y la contienda. A este proceso se le denomina orientaciones gubernamentales; estas buscan establecer en las distintas poblaciones, formas de sujeción y aceptación del proyecto minero a gran escala.

El objetivo central es explicar el proceso de orientación de actores, sus acciones y estrategias e intereses. Se plantean las siguientes preguntas ¿cómo actores y organizaciones interpretan y construyen una situación conflictiva y establecen determinadas estrategias en relación con esta?, ¿cómo los actores implicados disputan públicamente sus intereses y buscan solidaridad y legitimidad de amplios sectores de la sociedad?
Primero se plasmará el fenómeno a investigar: la minería y su dimensión política, resaltando el contexto en América Latina, sus efectos y características centrales a partir de los conflictos que generan en las distintas comunidades donde se pretenden, o se han implementado este tipo de proyectos a gran escala. Segundo, se realizará un breve estado de la cuestión, donde se resalten las principales perspectivas sobre el fenómeno a investigar y la pertinencia de la indagación. Tercero, establecer unos aspectos conceptuales vertebrales de la misma: conflicto social, contienda política, procesos de orientación colectiva, resaltando la importancia de estos para el problema a investigar. Cuarto, se reconstruirá el proceso organizativo, resaltando actores e intereses, mecanismos intervinientes, dinámicas y el proceso de orientación; seguidamente se estudiará el proceso de orientación institucional y gubernamental, y se cerrará con una síntesis de lo indagado.

Sobre este proceso se argumenta que la forma endógena en la conformación de la lucha social, los conflictos que anteceden al megaminero y el papel que desempeñarían sectores externos serán fundamentales para construir una 'secuencia' dinámica articulada sobre unas condiciones de vida propias de los actores locales sociales populares que tejieron alrededor de la minería pequeña y tradicional unas condiciones de vida propias, que se constituyeron en objeto de disputa. Por último, en esta dinámica fueron relevantes el papel del mecanismo relacional y su relación con el juego político.

Tratar de situar sucintamente el concepto de conflicto social se vincula fuertemente en cómo se conciba la realidad social y su funcionamiento. Podemos encontrar dos vertientes reconocidas ampliamente en la comprensión de los conflictos.

Una corriente consensualista, donde cualquier sistema social tiende a la autocompensación entre actores, fuerzas, articulación y funcionamiento. El conflicto social, en esta vertiente, es una expresión anómala del orden 
social. La otra perspectiva parte del supuesto que toda sociedad encierra contradicciones, objetivos e intereses contrapuestos. De tal forma, el conflicto es inherente a cualquier sociedad (Lorenzo, 2001, p. 237).

Se asume el conflicto como una relación social caracterizada por su oposición de los distintos elementos (objetivo y/o subjetivo), procede de las estructuras ${ }^{3}$, de las unidades sociales (Dahrendorf, 1966), y afectan a amplios o considerables sectores de la población. En este mismo sentido, el sociólogo alemán Lewis Coser establece que un conflicto se torna social cuando trasciende lo individual, y procede de la estructura de la sociedad, con una función integradora, al cohesionar identidades y delimitar grupos sociales (Coser, 1961). En todo conflicto social se manifiesta el desigual reparto del poder en los grupos sociales, estos aparecen en razón del poder y acerca del mismo (Dahrendorf, 1966, p. 192). Resalta el origen estructural de los conflictos sociales, junto a las relaciones de dominio que se configuran en las dinámicas sociales, sin posibilidad de sustraerlo de los intereses latentes que se adhieren a las posiciones sociales.

Desde la vertiente no consensual y no negativa del conflicto, autores como C. Wright Mills, (1994), Tom Bottomore, (1975), Ralf Dahrendorf, (1966) y actor importante para comprender los conflictos sociales la distribución de la riqueza, del poder y del estatus. El conflicto social trasciende a los individuos, y fundamentalmente es un aspecto básico del cambio social, al permitir dirimir diferencias y desigualdades entre colectividades, facilitando nuevos modelos de integración social.

Tratando de establecer una comprensión amplia de los conflictos sociales, no podemos dejar de referirnos a la obra del sociólogo noruego Galtung (2003). Este autor señala que los

3 Por estructural se hace referencia a un marco de condicionamientos y un conjunto de elementos relativamente persistentes en los sistemas sociales, con continuidad en el tiempo y espacio; poseen los rasgos más permanentes en la vida social, que otorgan solidez en el tiempo y espacio (Múnera, 1998). conflictos en una sociedad son crisis y oportunidad, estructurales y connaturales a la condición humana. Tiene como núcleo objetivos incompatibles, estos no se solucionan, tienden a transformarse, se refieren a la estructura de un orden social, y como tal tiene como sustrato relaciones de poder, que se localizan desde tres espacios: micro, meso y macro.

Complementando el planteamiento anterior, Melucci (1975, citado en Múnera, 1998) realiza una distinción pertinente entre conflicto y contradicción; hace referencia a la oposición de clase, y como tal en relación con las estructuras por la apropiación y control del cambio histórico, de esta forma, el conflicto social señala la importancia de los recursos que una sociedad usa para orientar sus prácticas. Por otro lado, la contradicción hace referencia a la incompatibilidad entre elementos o niveles de la estructura social.

Se entiende por conflicto social toda relación social que se caracteriza por una oposición de intereses, donde está en juego el control de recursos, tanto materiales como simbólicos, fundamentales para orientar las prácticas de una sociedad. Esta relación social, caracterizada por la oposición, bien puede ser objetiva o subjetiva; se refiere de forma central a las estructuras de una sociedad y amplios sectores sociales, donde se pone de manifiesto la posibilidad de cambio y donde los actores sociales y políticos buscan resolver una contradicción social. El conflicto social se refiere a una oposición abierta, o latente, por controlar recursos materiales, simbólicos, culturales y económicos de una sociedad, donde se disputan las orientaciones y las prácticas de estas dimensiones de toda sociedad, y que afecta amplios y diversos sectores sociales, evidenciando las distintas relaciones de poder que se tejen resultado de estas mismas luchas y tensiones.

El componente público y abierto hace referencia al Estado, sea como actor o mediador, es decir, el Estado abriría mediaciones institucionales y organizativas; actor indispensable en la trasformación y/o resolución del conflicto, al 
mismo tiempo, participa en esta relación social de oposición, al igual que otros actores (Múnera, 1998).

Empíricamente Dahrendorf (1966) resalta la necesidad de distinguir el conflicto social en tres momentos: una fase de conformación en las relaciones sociales; una segunda sería la cristalización, es decir, la evaluación consiente de los intereses latentes, adquiriendo concreción visible y articularse con otros elementos sociales y otros conflictos; y el tercer momento del conflicto social son las identidades visibles. Para este autor, el conflicto social puede variar dependiendo de dos dimensiones: la intensidad, entendida como grado de participación de los afectados, es decir, la energía invertida; y la violencia, entendida como una forma de expresión, un medio que eligen los actores.

Para una compresión y explicación del fenómeno del conflicto social, se debe tener presente los anteriores componentes, características en los distintos niveles y dimensiones, no deben quedarse solamente en la descripción, sino poder comprenderlos críticamente en su complejidad práctica, funcionamiento, y lógicas internas y externas; además se debe poder sistematizarlos de tal forma que sean accesibles y manejables por la racionalidad humana.

En todo conflicto social en su dimensión objetiva se resaltan tres aspectos fundamentales: la dimensión pública, el conflicto y cooperación, y lo que tiene que ver fundamentalmente con la distribución de recursos materiales y/o simbólicos (Lefwich, 1987, p. 123). Es necesario aclarar, en concordancia con la perspectiva teórica asumida para esta indagación, que el carácter político de los conflictos sociales en las sociedades actuales no se limita en los círculos de gobierno, o partidos políticos de las sociedades modernas (Lefwich, 1987). Los conflictos sociales se inscriben en un marco extensivo de la política y su dinámica no centrada en las instituciones públicas y de gobierno. Por el contrario, estos se desenvolverían en el ancho espectro de lo político, donde el Estado sería el eje de la actividad política, pero no centrada en los aparatos burocráticos o en las dimensiones legales, sino en la compleja red de relaciones e interacciones sociales entre Estado y sociedad civil.

De los conflictos mineros a gran escala se resalta la dimensión política por determinar y controlar las condiciones de vida, los recursos materiales y simbólicos de una sociedad, que tienden a afectar a diversos actores y sujetos sociales, donde la dimensión pública se constituye en un aspecto central en el proceso de génesis y desarrollo de los conflictos, y donde son fundamentales relaciones no solo de dominación y resistencia, sino cooperación y alianzas.

Estos elementos permiten señalar que todo conflicto social tiende a ser político, pero no todo conflicto político es social. De tal forma que la dimensión política es solo un componente del conflicto social. Si bien en ambas categorías son fundamentales las relaciones de poder, solo en el conflicto social se alude al carácter estructural de una sociedad y a relaciones de oposición. En la política se pueden establecer relaciones de cooperación, contradicción y oposición. Por último, y de forma fundamental, en la política es donde los conflictos sociales se desarrollan y adquieren visibilidad. Es en esta donde el conflicto social puede resolverse o adquirir expresiones violentas o de negación de los adversarios, de los diversos intereses y actores. La política es el espacio donde se disputan el control y orientación de un campo social en una sociedad, adquiriendo diversas trayectorias. Esta disputa por el control y orientación de un campo social, por recursos materiales y simbólicos intervienen un conjunto amplio y diverso de actores sociales y políticos, institucionales y no institucionales, en un ámbito concreto donde se emplean distintas acciones, entre estas, las acciones colectivas.

Por último, conflicto social y política no se deben pensar de forma separada. Lo constitutivo de toda sociedad sería el conflicto, la diferencia de intereses, necesidades, capacidad de influencia y experiencias de los actores y sujetos en la estructura social. De igual forma, es necesario pensar tanto el conflicto social como su 
dimensión política en clave de maniobra, estrategias y capacidad de reversión de los actores.

Lo mencionado hasta este momento permite señalar que los conflictos y disputas que se dan en proyectos mineros a gran escala aluden a las siguientes dimensiones fundamentales: primero; las relaciones de poder, expresándose en procesos de interaccion, conflicto, negociación, contradicción y oposición de distintos actores e intereses; segundo, los conflictos alrededor de proyectos mineros son esencialmente conflictos sociales, donde la política adquiere mayor significado por controlar recursos materiales y simbólicos atribuibles a los territorios, sus recursos y/o usos. En suma, este tipo de conflictos sociales, y su dimensión política, son disputas por la orientación en las relaciones sociedad y territorios, orientaciones que delimitan determinadas prácticas y relaciones sociales en una sociedad específica.

Para distinguir entre conflicto social y contienda política se recoge lo que plantean (Mc Adam, Tarrow y Tylli, 2005). Contienda política es una expresión, un momento y, fundamentalmente, un tipo de interacción episódica y pública, donde distintos actores y sujetos sociales y políticos disputan un objeto u objetos que afectan intereses y condiciones de vida de una amplia porción de población. Esta interacción se caracteriza por la presencia de relaciones de oposición y polarización, formación de identidades y, fundamentalmente, acciones colectivas contenciosas y disruptivas que se concretan para crear desafío, incertidumbre y solidaridad de otros sectores de la sociedad. Llegado a este punto, se plantea que entre las categorías de conflicto social y contienda política, la bisagra que las articularía es la política y las relaciones de poder que se gestan en ambas.

En cuanto a la metodología propuesta, es una revisión documental a partir de fuentes primarias y secundarias articuladas mediante un contrapunteo entre lo que podríamos denominar "discurso institucional" y "discurso alternativo". Con respecto al discurso institucional, las fuentes primarias se han relacionado mediante la información obtenida de las entidades y representantes de instituciones; se consultaron documentos públicos, informes, comunicados de prensa, la normatividad vigente, y videos publicados en la red por agencias oficiales y no oficiales. En relación con el 'discurso alternativo', las fuentes consultadas también fueron de orden primario: entrevistas a líderes sociales y comunales, comunicados escritos impresos y en la red, estudios e investigaciones sobre el tema, realizadas por distintas organizaciones nacionales e internacionales.

Esta forma de obtención de información permitirá reconstruir el proceso desde los actores, los intereses y las acciones, establecer cambios en el desarrollo del conflicto, capturar el proceso, identificar y (re)construir un fenómeno social y, fundamentalmente, establecer una comprensión de este. Lo fundamental es analizar y tomar estas distintas fuentes en clave de relaciones de poder, dentro de las dinámicas políticas y lo que estaría en juego con estas.

\section{Minería y conflicto en América Latina}

Desde la configuración del capitalismo en el siglo XVI (Wallerstein, 2001), América Latina se convirtió en lugar de extracción de recursos naturales, donde los costos de producción se reducen al máximo, a costa de altos costos socioeconómicos y ambientales, que son externalizados a las comunidades y poblaciones afectadas (Delgado, 2013).

Los megaproyectos extractivos se caracterizan económicamente por pocos encadenamientos productivos y son socio-ambientalmente negativos (despojo de tierras, uso masivo de aguas y conflictos por el acceso y uso, además del usufructo de otros bienes comunes). Al final de la extracción y producción del material se desechan materiales con altos niveles de contaminación. Costos que no son tomados en cuenta en la producción minera (Delgado, 2013).

Con estas características geopolíticas se configuran los marcos institucionales y de 
regulaciones estatales que determinan la extracción de recursos en cada país, delimitando los procesos de resistencia, oposición y luchas, junto con negociación, mimetización y resistencias silenciosas. Lo anterior es fundamental plantearlo, dado que en esta dinámica histórica e internacional es que se inscriben los conflictos de proyectos mineros y se configuran las contiendas políticas.

Las actividades mineras a gran escala se constituyen en un motor de conflictos en regiones rurales y olvidadas por los Estados o con debilidades institucionales y exclusión social. Es necesario mencionar que la actividad minera se solapa con disputas históricas por la expropiación de recursos, que constituyen una matriz esencial de las formas de vida de comunidades rurales, indígenas, afrodescendientes, y donde se pone en disputa el agua, la tierra y la autonomía alimentaria (Machado, 2011).

En este tipo de conflictos existen ciertas constantes donde se pretenden realizar estos grandes proyectos mineros. Las comunidades demandan información en las etapas iniciales; se establecen procesos organizativos, búsqueda de información de la ciudadanía para la toma de decisiones. Por otro lado, las empresas usan una gama amplia de propaganda y publicidad sobre los proyectos, uso de tecnología de punta, empleo y activación económica local y regional, comercio y transporte. También explotan necesidades sociales y económicas, prometiendo traer servicios que el Estado no logra suplir (Padilla, 2012). Siendo más precisos, las empresas logran entrar a las comunidades enunciando suplir el papel del Estado históricamente ausente, con proyectos de infraestructura educativa, salud, carreteras. Estas serían las ofertas que traen las empresas a cambio de que la comunidad dé vía libre a los proyectos mineros.

Los procesos organizativos y de resistencia de las comunidades en conflictos sobre proyectos mineros a gran escala son la antesala de las contiendas políticas. En esta última se forman identidades colectivas antagónicas, procesos de polarización, lucha abierta, altamente tensionante y desarrollo en el ámbito de lo público (Mc Adam, Tilly y Doug, 2005). Parte constitutiva de los conflictos y de la contienda política es lo que autores como Tarrow (2004), Gamson (1999), Benford y Hunt (1992) y Rivas (1998) denominan marcos de orientación, es decir, la creación de orientaciones e interpretaciones comunes sobre lo que se estaría disputando. Estas serían las atribuciones colectivas que les dan los individuos y actores en medio del conflicto, y que permiten procesos de movilización a través del consenso y la definición de una situación que es mediada por procesos de acción colectiva y están en relación directa con la forma y el tipo de la contienda política. Elementos atribuibles igualmente a los actores oficiales y privados.

En los procesos de contiendas políticas, los gobiernos centrales y las empresas mineras tienden a estigmatizar a los opositores a este tipo de proyectos señalándolos de rechazar la modernidad, el desarrollo y el crecimiento económico del país, o por querer volver a una edad de piedra. Por otro lado, en cuanto a las organizaciones y comunidades, son importantes los intercambios de experiencias y visitas a lugares en que se realizan los proyectos megamineros (Toro, 2012). Estos serían mecanismos que permiten construir y producir, desde las organizaciones y actores colectivos, valoraciones a través de la observación y constatación de los efectos sociales, económicos y culturales resultado de la llegada de este tipo de proyectos de gran escala. Las comunidades y organizaciones locales y rurales han usado un conjunto amplio de acciones legales y administrativas, movilización, cabildeo, declaraciones públicas, alianzas y denuncias en medios de comunicación (Bebbington, 2009). Las consultas ciudadanas se han convertido en un mecanismo para demostrar la fuerte oposición social (Toro, 2012; Padilla, 2012).

La lucha de las comunidades y la cristalización de un conflicto a la contienda política la mayoría de las veces tienden a estar acompañada de la vulneración de derechos humanos, represión, intimidación, amenazas y criminalización. Igualmente en los procesos de legitimación 
y aceptación, las empresas mineras han comprendido que no pueden descuidar lo social, y que invertir en la cooptación y división de la comunidad es fundamental. Y, las autoridades y organizaciones sociales, comprenden la importancia de consolidar la voluntad popular y la cohesión, tomando conciencia de los procesos de consulta como principio de democracia, combinando estrategias como la presión social, demandas internacionales, denuncias de las deficiencias técnicas en los proyectos, además de visibilizar alternativas de desarrollo más incluyentes y ecosostenibles generadas desde las propias comunidades, sus experiencias y modos de vida (Cancino, 2012).

\section{Estado de la cuestión}

En una breve revisión de la literatura sobre este fenómeno se encuentran cinco perspectivas con dos entradas generales. Cada una tiene una interpretación propia y entradas distintas para explicar el objeto de indagación. La ecología política ha privilegiado las relaciones sociedad-naturaleza, la producción de capital, los pasivos ambientales, y cómo influyen o no las comunidades en los proyectos mineros. La economía y ecología política han tratado de explicar los conflictos según los intereses económicos en juego, principalmente cuando los conflictos mineros se han resuelto a favor de la industria minera y cómo entra la comunidad a recibir o disputar beneficios económicos por esta actividad. Como tal, incluye: relación, definición y acceso a recursos, con demandas sociales por tierras, autonomías y la conformación estructural de la sociedad. La sociología del conflicto se ha preocupado por explicar las acciones de los actores y cómo se realiza el conflicto en lo público. La ecología política explora las relaciones entre naturaleza, desarrollo, capital y movimientos sociales, en las estrategias desde lo local y la esfera cultural de las mismas en la conservación de la biodiversidad (Escobar, 2005) Esta perspectiva de análisis de los conflictos socioambientales enfatiza las luchas por el acceso y control de recursos naturales definidos como conflictos ecológico-distributivos, donde es fundamental el uso de lenguajes de valoración (Martínez- Alier, 2004),
La revisión de la literatura también permite pensar que los conflictos socioambientales estarían atravesados por otros elementos que les otorgarían rumbos diferentes a los referidos a lo ambiental propiamente dicho. Y en la medida en la que se vuelve público tiende a incorporar diversos temas de otros conflictos existentes, incluyendo otros sectores y otorgando más causas a la disputa (tipo y formas desarrollo, derechos humanos, democracia y ciudadanía). Igualmente, en la literatura existente, el conflicto aparece con relación al contexto institucional, las prioridades y percepciones de los actores y una historia política previa en relación con esos territorios.

Por otro lado, está presente en la literatura una mayor tendencia a explicar los conflictos socioambientales con tres variables independientes principales: inclusión/exclusión de comunidades en el modelo de desarrollo (Cisneros, 2007; Romero, 2011; Ortiz, 1999), demanda de derechos y efectos de la industria extractiva (Garvay, 2011; Wagner y Goraud, 2011), y presencia/ausencia del Estado (Fontaine, 2006; Del Pozo, 2010). La literatura parece sugerir que los conflictos sociales alrededor del uso del territorio aparecen por demandas más amplias (Vacaflórez y Lizárraga, 2005), por regulación del Estado sobre la industria, por prácticas extractivas de las industrias mineras más sensibles y una fundamental demanda de las comunidades por ser escuchadas e incluidas.

Por último, la literatura resalta tres elementos que pueden incidir en cómo se resuelve el conflicto mismo: oportunidades abiertas en los distintos momentos del proyecto extractivo; el uso o no de la acción directa por actores y organizaciones locales o institucionales; y la capacidad de los movimientos y organizaciones de tender puentes y relaciones de colaboración con gobiernos locales y regionales, o con otras organizaciones para crear redes políticas y de acción (Bebbington, 2013).

Del caso particular de investigación se resalta la indagación de Ramírez (2012) situándose en la ecología política y la sociología del conflicto al estudiar la dinámica de la minería local y los procesos de arraigo territorial que esta actividad genera, los conflictos que se producen por la llegada de la 
minería a gran escala. Ramírez (2012) concluye que la modificación en el sentido de territorio social y culturalmente dotado por las comunidades se trasforma en territorio para beneficio económico y calificado como territorio vaciante a causa de la necesidad de la compañía minera.

La literatura revisada se preocupa por las causas de los conflictos mineros, el papel del Estado en la regulación del mismo y las demandas de actores en mayor participación, pero dejan de lado el conflicto social y político de los mismos, la identificación de una problemática con fines de movilización en el ámbito de lo público, las relaciones entre actores sociales y populares, actores institucionales, sus formas y estrategias de enmarcar el conflicto y la contienda. Dado esto, se plantea la siguiente cuestión: ¿Cómo se configura el conflicto social y la contienda política entre actores con sus respectivas formas y procesos de orientación en el caso del proyecto minero de Marmato, Caldas durante 2007-2012?

Situada la minería a gran escala y sus aspectos conflictivos, con relación a comunidades, organizaciones, actores sociales y políticos, las dimensiones estructurales que ella encierra, es decir, su aspecto esencialmente político, y a partir de esto, la relevancia del Estado y sus instituciones. Igualmente se resaltó que alrededor y en el centro de los conflictos mineros aparecen distintos actores, múltiples y contradictorios intereses, distintas acciones, estrategias y mecanismos intervinientes que condicionan las formas de las luchas abiertas y los procesos de movilización por los territorios y sus formas de vida. Estos solo constituyen una forma en la que el conflicto minero se puede presentar dependiendo de las relaciones e interacciones de los distintos elementos resaltados en los contextos políticos, económicos y sociales.

\section{Breve descripción del caso: Marmato, Caldas}

Este conflicto se conforma como respuesta al proyecto de oro a cargo de la empresa Medoro Resource y posteriormente la Gran Colombia Gold. El municipio de Marmato, ubicado en el departamento de Caldas, se caracteriza por tener presencia minera artesanal desde antes de la Colonia. Dos elementos se han presentado: uno son los cambios en el control de propiedad y normas de las minas, el otro la tecnología usada en la extracción y procesamiento del mineral (Sandoval, 2012). En Marmato existen dos formas de explotación: la veta y el barequeo ${ }^{4}$. La veta se caracteriza por socavón, rompimiento de la roca, uso de la fuerza del minero, del taladro y de pólvora, bajo rendimiento y grandes daños ambientales resultado de la pequeña minería (Ramírez, 2012).

Los guacheros 5 , poseedores de minas y trabajadores independientes de otras regiones ocuparon las minas, y conformarían la Asociación de Mineros de Marmato. En un inicio, se movilizaron esporádicamente como respuesta a las intenciones de desalojo, y participaron en marchas y manifestaciones públicas en contra del proyecto de cielo abierto de la empresa. Su interés principal fue conservar la forma de obtener ingresos, resultado de la pequeña y mediana explotación. Los poseedores de minas son pequeños y medianos empresarios mineros que establecieron una pequeña infraestructura de entre 10 y 50 trabajadores. La explotación de la Gran Colombia Gold los puso en peligro (Sandoval, 2012).

El Comité Cívico por la Defensa de Marmato es la respuesta más clara de organización de la comunidad ante la llegada de la multinacional minera. Compuesta por organizaciones de base, líderes comunitarios, educadores, representantes de organizaciones políticas, comunidades indígenas y afros, no vinculados necesariamente con la minería. Básicamente la posición de esta organización es de rechazo al proyecto de cielo abierto por efectos ambientales, contra el reasentamiento del pueblo que implica este proyecto y el monopolio de la empresa para la

4 Se entiende por barequeo una forma tradicional y comunitaria de extracción de oro de aluvión. Se emplea principalmente trabajo manual y artefactos rústicos, sin maquinaria alguna.

5 Los guacheros son el nombre de los trabajadores de las minas que laboraban para la compañía canadiense Goldfiends y posteriormente Medoro Resource. Posterior a la compra de los títulos, muchos de estos trabajadores fueron despedidos. Estos trabajadores tomarían por vías de hecho sus antiguas minas para laborar en estas, llamándose a sí mismos guacheros. 
oferta laboral, además del desgaste de los recursos mineros en tan corto tiempo, dejando a futuras generaciones sin subsistencia económica. En esta disputa la organización crea un lenguaje y una legitimación como actor, a partir de reivindicar valores históricos y culturales del municipio y de la población alrededor de una historia minera de larga data, y de una tradición y cultura minera propia.

Se resalta la presencia de comunidades indígenas, presencia de mineros artesanales y pequeña minería como actores sociales. Igualmente se manifiesta al interior, divisiones y sectores que tienen posiciones distintas y enfrentadas por el proyecto.

\section{Marmato, Caldas. Actores locales y resistencia endógena}

$\mathrm{Al}$ establecer la primera fase de orientación colectiva en Marmato, es necesario mencionar que antes de la llegada de los proyectos mineros a gran escala, la población del municipio se caracterizó por la ausencia de procesos organizativos mineros, campesinos e indígenas; pero sí existían procesos comunitarios rurales de gran participación comunitaria, emprendiendo proyectos que buscaban beneficiar a gran parte de la comunidad (Observatorio de Conflictos mineros en América Latina). Por otro lado, Marmato y la zona cafetera aledaña se caracterizan por una fuerte presencia de adhesiones políticas bipartidistas, es decir, esta zona se caracterizó por acentuados procesos de identificación política definidas por el bipartidismo entre conservadores y liberales, así como procesos de memoria histórica condicionados por los procesos de violencia entre estos mismos.

Es pertinente mencionar la influencia que tuvo en estos procesos organizativos las comunidades indígenas del Cauca y su consolidación a finales de los años de 1980. En cuanto al proceso organizativo en Marmato, el CRIDEC (Consejo Regional Indígena del Caldas), la ONIC, (Organización Nacional de Indígenas de Colombia) y el CRIC (Consejo Regional Indígena de Cauca) tuvieron fuerte influencia, en cuanto a organización y experiencias de lucha. Principalmente el CRIC fue de gran relevancia para el asesoramiento de los mineros y de sectores que se autodefinían como inconformes con el proyecto de la minera Medoro Resources (Observatorio de conflictos mineros en América Latina). En el departamento de Caldas, el CRIDEC tuvo gran importancia organizativa y de lucha política, pero en el caso de Marmato no existió esta experiencia de organización de la población indígena ni afros hasta el 2006.

El Código de Minas del $2001^{6}$ generó gran inconformidad, fue valorado negativamente por los pequeños y medianos mineros por permitir la apertura al capital trasnacional y no establecer definiciones y distinciones claras sobre las obligaciones de cada sector minero. Este código generó inconformidades para la población local de Marmato, pero no generó procesos de movilización por parte del sector minero de pequeña y mediana escala; sí fue un antecedente que posteriormente, resultado del proceso de orientación, se identificaría como parte de un problema a disputar ante el gobierno central.

En el 2000 llegaron algunas compañías a comprar minas, pero sin causar en la población inquietud o desestabilización social. Entre el 2004 y 2005 llega la compañía Colombia GoldFields Ltda., a comprar y solicitar títulos mineros. Paralelamente se inicia el proceso de conformación del Cabildo Indígena de Caramanta, conformado principalmente por la comunidad indígena Embera Chami, la cual empezó a aprender del proceso organizativo del Cabildo de Riosucio (Lideresa indígena y exgobernadora Cabildo Indígena Caramanta. 29 de abril de 2014. Entrevistada por Eduardo Martínez Torres. Marmato, Caldas).

Con la llegada de la compañía minera y su propuesta concreta de comprar minas y solicitar los títulos legales, se generó en la comunidad una ruptura del equilibrio social, pero todavía, sin

6 Este código ilegaliza al pequeño minero, y establece condiciones legales, técnicas y de capital que solo pueden cumplir las grandes empresas mineras (Triana, 2001). 
realizar la construcción del problema, ni mucho menos procesos y formas de insubordinación abierta y activa (Aguirre, 2010). "La experiencia de nosotros cuando llegaron las empresas mineras tratando de desarrollar proyectos, cambió rotundamente la vida de los marmateños, porque acá se vivía una vida tranquila, sin problemas" (líder minero y comunitario, fundador del Comité Cívico Prodefensa de Marmato, 25 y 29 de abril de 2014. Entrevistado por Eduardo Martínez Torres, Marmato, Caldas).

\begin{abstract}
La minería acá en Marmato se había desarrollado en un ámbito muy tranquilo, muy saludable hasta que empezaron a aparecer estas empresas en explotar a Marmato, lo que llaman la gran minería o las trasnacionales, hasta ahí llego la paz de los marmateños... cuando llegaron las multinacionales empezó el caos (líder minero y comunitario, fundador del Comité Cívico Prodefensa de Marmato, 25 y 29 de abril de 2014. Entrevistado por Eduardo Martínez Torres, Marmato, Caldas).
\end{abstract}

Estas valoraciones iniciales de un antes y un después de la vida de los marmateños no significó la identificación de agravios, practicas ilegítimas, indignación, ni exigencias de la multitud a las autoridades locales ni nacionales.

La compañía Colombia Goldfields y su posterior cambio a Medoro Resources llegó con un lenguaje de cambio sustancial de las condiciones de vida de la población: generar mejores condiciones de empleo, educación, salud y mejorar los servicios básicos. Todo esto anclado en un fuerte discurso desarrollista y progreso, a cambio de permitir el proyecto de minería a gran escala. Esta armazón desarrollista y de progreso produjo en la comunidad local una fuerte división entre los que están a favor del proyecto y los que no lo percibían de la misma forma.

Así, un sector bastante reducido de la población de Marmato empezó a tener la inquietud de lo que implicaba un proyecto de minería a gran escala. Un sector comenzó a construir un problema buscando información externa; estaba conformado por algunos mineros que no vendieron sus minas, además de indígenas que han trabajado la minería históricamente. Las inquietudes del grupo que no tenía una visión positiva del proyecto se torna en oposición clara pero reducida, resultado de dos procesos distintos. Primero, unos incipientes encuentros y asesoramientos con organizaciones externas, que permitió conexiones de sectores sociales como mineros e indígenas, creando y definiendo intereses, lazos y conexiones comunes, sumado a los desprendimientos de tierra ocasionados en 2006 y 2007. Este último fue un primer punto de inflexión que permitió pasar de una injusticia tolerable a unos agravios e injusticia definidos como intolerables. El desprendimiento de tierra acaecido en septiembre del 2006 fue manejado por la Colombia Goldfields y el gobierno central a través de los medios de comunicación para justificar la necesidad de trasladar el casco urbano de Marmato a la región del Llano. A raíz del manejo que le dio la compañía minera y el gobierno central de iniciar el proceso de traslado de la plaza central, el colegio y las instancias administrativas locales, junto con unos locales comerciales se decide crear el Comité Cívico Prodefensa de Marmato.

Estas experiencias, que llegan a constituirse en lo que Brito (2015) denomina experiencias catalizadoras permitieron resignificar la experiencia anteriormente mencionada a través de ejercicios colectivos de (re)significación y (re)interpretación como injustas. Desde una ética popular, se construyen unos primeros mecanismos cognitivos (McAdam, Tarrow y Tilly, 2005) que logran alterar interpretaciones colectivas e individuales de la situación. Estas se construyen alrededor de unas injusticias y un problema social, realizando los primeros consensos sobre la necesidad de crear procesos organizativos que respondan a la llegada del proyecto minero a gran escala.

El Comité Cívico tuvo inicialmente un carácter reactivo resultado de la interpretación del sector que primero demandó mayor claridad de la compañía y del gobierno central, con un asesoramiento incipiente de organizaciones externas. Y luego reaccionó ante la iniciativa de trasladar el pueblo a consecuencia de los derrumbes de tierra. 
Hasta este momento es necesario mencionar lo siguiente: la compañía minera Colombia Goldfields inicia su proyecto paralelamente a la iniciativa del sector indígena de Marmato de conformarse como Cabildo indígena. En esto fue fundamental el acompañamiento inicial de CRIDEC, al vincular sectores sociales que antes no tenían mayor relación e incorporar y dar experiencia en procesos organizativos, crear intereses compartidos sobre el problema social, articulándose a un proceso inicial de inquietud y preocupación de una parte de la población de Marmato sobre lo que implicaría un proyecto de minería a gran escala, asesorado por organizaciones externas. La creación del Comité Cívico y el papel que hasta ese momento había tenido el CRIDEC en el acompañamiento del Cabildo Indígena de Caramanta permitiría que las inquietudes, los agravios, lo injusto se tornaran en algo inadmisible, es decir, una problemática que se tornara en una oposición abierta y activa.

En este sentido la oposición al proyecto minero a gran escala tuvo la característica de conformarse de adentro hacia afuera, que si bien en el transito del conflicto social a la contienda política, no se puede negar la posición favorable de la población al proyecto minero, esto se fue trasformando por el empleo de mecanismos creados e impulsados por el Comité Cívico Prodefensa de Marmato. Este logró que confluyeran distintos sectores y enclaves sociales que estaban previamente desconectados o con conexiones mínimas. Con lo anterior, se resalta el tránsito de un conflicto social a la contienda política, resultado del aumento en las interacciones de sectores externos que lograron converger, conformando demandas e intereses comunes; además, se acuerda una hoja de ruta común, sobre la necesidad de establecer acciones comunes para defender el pueblo y las formas de vida creadas alrededor de la minería pequeña y tradicional. La contienda política es una primera reacción frente a una problemática, es decir, identificar unas injusticias, amenazas y unos causantes. Se establecen las primeras formas de apropiación social de la situación. Estas últimas se construirían principalmente desde el Comité Cívico, con una base social y organizativa pequeña, pero consolidada y en crecimiento, que sería fundamental para conectar a actores y organizaciones locales, en el ámbito regional, nacional e internacional.

En este trayecto, los líderes locales encontraron importantes factores que desestabilizaron la dinámica del conflicto social a la contienda política local. Primero fue el temor que percibían los líderes, un gran temor que no les permitía enfrentarse de frente:

\begin{abstract}
El terrorismo psicológico nos mantenía reprimidos. Nosotros queríamos hacer algo grande, enfrentarnos, hacer un paro, pero nos decían que nos mandarían la Policía, los grupos al margen de la ley, comenzamos a ver gente rara... Entonces por ese miedo de que mataran a alguno para desestabilizar al Comité Cívico, se fueron saliendo" (Entrevista ex gobernadora indígena y cofundadora de Parcialidad Indígena Cartama y Comité Cívico Prodefensa de Marmato. 30 de abril, 2014 y 05 de mayo 2014. Entrevistada por Eduardo Martínez Torres. Marmato, Caldas).
\end{abstract}

De esta forma, la percepción e identificación que otorgan y construyen los actores locales en abierta oposición y las estrategias y acciones de respuesta condujeron a una serie de valoraciones distintas a través de actividades de concientización, talleres de influencia local para activar políticamente a la población local.

Durante el 2008 y el 2009 se da una trasformación cualitativa de la lucha definida por dos elementos. El primero, es la definición por parte del Comité Cívico de unos elementos a disputar ante la compañía minera y el gobierno central enmarcados centralmente desde lo que Orellana (1999) denomina espacios de vida. Este proceso de orientación le permitió captar la opinión pública y construir lazos de solidaridad con otros sectores que apoyaron la lucha que se inició de forma local y centralmente endógena, para adquirir ya en el proceso de consolidación una oposición abierta y activa. Adquiriendo niveles de la disputa en lo regional y nacional.

Lo que está en juego en esta primera fase de la contienda política, para los dos sectores 
principales: pequeños y medianos mineros e indígenas, es el control y definición del territorio y los recursos, pero en este último caso, vinculado a la práctica minera tradicional. Por otro lado, con la llegada de la compañía minera y su proyecto, las adherencias de amplios sectores de la población local. Lo que estaría en disputa, son igualmente formas distintas de controlar el territorio, sus recursos y las relaciones que se construyen alrededor de estos espacios. Por eso, lo que se está jugando, significaría mejores condiciones de vida material, así como el control del territorio, sus recursos y las posibilidades de participar de una mejor forma en las nuevas dinámicas que publicita localmente la compañía minera. La disputa local de las poblaciones afectadas, que se definen de forma heterogénea, lo que estaría en juego se articula con promesas de acceso a riqueza que se refleja en polarizaciones internas de las comunidades locales.

\subsection{Comité Cívico Prodefensa de Marmato: mecanismo relacional y la relevancia de otros sectores}

Para el 2009 es posible hablar de contienda política; la lucha que realizaron las organizaciones y sectores que desde el principio se opusieron al proyecto transforman un problema social en una problemática con unas causas y agentes del problema: "La gente solo andaba con la empresa... decirle y abrirle los ojos a la gente es muy duro, hasta el 2007 fue muy duro pero ahora es de tú a tú" (entrevista a ex gobernadora índígena y cofundadora de Parcialidad Indígena Cartama y Comité Cívico Prodefensa de Marmato, realizada por Eduardo Martínez Torres, 30 de abril de 2014 y 05 de mayo de 2014, Marmato, Caldas). En este segundo momento, las estrategias y las formas de dividir a la comunidad local con prebendas, capitalizar las condiciones de marginalidad y pobreza son explotadas por la compañía para lograr lo que se denomina como el 'pase social' al proyecto. Paralelamente, construyen procesos colectivos de (re)interpretación y (re)significación estratégica de las condiciones existentes como injustas e intolerables y que ameritan procesos organizativos. El CRIDEC se constituyó como mecanismo que facilitó la organización del Cabildo Indígena de Caramanta al capitalizar experiencias definidas como injusticias, ilegales e ilegitimas, procesos de apropiación social y formación de identidades locales. Mecanismos que a través de sus interacciones permitirán la aparición de procesos de oposición abierta y contenciosa.

El CRIDEC facilitó crear una estructura de movilización, es decir, una serie de canales colectivos y abiertos a través de los cuales se permitió básicamente movilizar, implicar y ampliar los niveles de la contienda. Esta organización, a través de su experiencia organizativa, lucha social y política, facilitó foros, talleres locales, difusión de otras problemáticas y experiencias nacionales e información de experiencias en otros países.

El papel del CRIDEC en aportar contactos y alianzas estratégicas, y la experiencia organizativa permitieron que la población y los líderes que no estaban a favor del proyecto respondieran a la necesidad de crear un comité que hiciera frente a los agentes que atentaban contra la estabilidad y continuidad del pueblo, facilitando la creación de una causa colectiva, logrando la formación de consenso mínimo (Klandermans, 1998) sobre lo que implicaba un proyecto de minería a gran escala. El Comité Cívico permitió congregar grupos e individuos diversos, pero indignados por las actuaciones políticas del gobierno central, regional y municipal. En este proceso, el CRIDEC fue la plataforma que aportó la experiencia organizativa y las alianzas estratégicas, y el Comité Cívico se conformaría como el mecanismo al que confluiría la población local, al disputarle el favoritismo de la población local al proyecto de la compañía minera. Por otro lado, el Comité Cívico, al haber consolidado una oposición local antiminera, de carácter endógeno y desde adentro expandir, irradiar y liderar movilizaciones contra proyectos mineros a gran escala y las trasnacionales.

El Comité Cívico, al observarse como mecanismo en el proceso de concientización, logró articulaciones fundamentales y estratégicas con sectores como la academia, estudiantes de 
universidades departamentales, colectivos independientes y organizaciones internacionales. Sobre este confluyeron no solo sectores que se solidarizaron, sino que se constituyó como referente de las luchas contra las trasnacionales en Colombia. Logró así ampliar el contexto de incidencia política, implicando a más actores en la contienda política y obligando a otros a tomar posición.

Este mecanismo se caracterizó por utilizar y combinar, en un momento, un lenguaje bastante cercano a las experiencias de la población y, fundamentalmente, desde la subjetividad construida alrededor del territorio y la minería. El lenguaje utilizado y la forma de encuadrar el objeto de disputa tuvieron un fuerte anclaje en la población minera e indígena que conforma el municipio de Marmato, que en la medida que se fueron aglutinando sectores que se solidarizaron, se tornó más complejo, se añadieron otros elementos, otros discursos que trasformaron el lenguaje inicial. Resultado de estas interacciones, del uso de los mecanismos y de la dinámica del contexto político y socioeconómico cambia lo que estaría en juego para los actores. Se daría lo que Mc Adam, Tilly y Tarrow (2005) denominan cambio de objeto. Esta trasformación alteraría las relaciones entre reivindicadores y los elementos en juego.

De esta forma, desde el 2009 hasta el 2012 el proceso de orientación logró movilizar a más sectores. Los actores y organizaciones locales concluirían que la contienda política ante el proyecto minero a gran escala debería pasar de forma importante por las vías de hecho que se decidieran. Así mismo, desde el 2009, localmente se tomó la decisión de defender sus espacios de vida con importantes alianzas políticas con el partido político Polo Democrático y las importantes acciones colectivas realizadas con organizaciones internacionales, que permitieron equilibrar la balanza ante la compañía minera, tejiendo una fuerza moral que se esgrimió primero ante la compañía, capitalizando importantes experiencias y acontecimientos (derrumbe de tierra 2006-2007, despidos de cerca de 850 mineros, junto a la destrucción de cerca de 10 molinos de beneficio y la muerte del párroco de Marmato en el 2011); estos hechos fueron experiencias catalizadoras de la población local, que el Comité Cívico supo explotar fuertemente a su favor. Fundamentalmente, les permitió construir un campo de protección local y nacional ante las acciones de la empresa y del gobierno central.

Por último, para el 2010, producto de los procesos de orientación de los actores y organizaciones locales, del encuentro y solidaridad con otros sectores de la sociedad, pero fundamentalmente resultado del proceso de conflictividad y contienda ante la compañía y el gobierno central, se puede hablar de una exterioridad constitutiva, una identidad compartida, donde ese "otro" (gobierno central y compañía minera) son identificados como los causantes de la amenaza a la existencia de los espacios de vida (Ortiz, 1999; Orellana, 1999), creados alrededor del territorio y la minería pequeña y tradicional como forma de subsistencia material.

\subsection{Activación de la historia desde espacios de vida, a la no entrada de trasnacionales: estrategias de orientación}

En este proceso de orientación, ¿cuáles fueron las ideas y los elementos que construyeron las organizaciones locales que permitieron ampliar los lazos con otras organizaciones, tener solidaridad de un amplio sector de la población $\mathrm{y}$, fundamentalmente, construir legitimidad de los actores?, ¿qué significa para las organizaciones locales el objeto central de su disputa y cuáles fueron las estrategias para ubicarlo en la escena pública?

La pequeña y mediana minería en Marmato se conformó como proceso económico y medio de subsistencia, que permitió crear procesos de pertenencia cultural y social. Construyó mecanismos de solidaridad $y$, fundamentalmente, se constituyó como un sistema de regulación social, con estructuras de sociabilidad y mecanismos específicos de regulación aceptados socialmente. A partir de este tipo de minería se 
creó un habitus productivo y minero (Sandoval, 2012)7. La minería tradicional, y la posterior llegada de la pequeña y mediana a principios del siglo XX, permitió construir "fuerzas, mecanismos de regulación de los recursos disponibles" (Aguirre, 2010, p. 15), los cuales serían trastocados y amenazados con la llegada de la compañía minera, generando desestabilización social y cultural, que a través de ejercicios intelectuales los trasformarían de agravios tolerables en injusticias ilegitimas.

Lo que estaban disputando las organizaciones locales era una serie de elementos, que incluyen mantener su formas de vida, el medio de sustento, pero también la posibilidad de decidir sobre grandes proyectos que pueden afectar la forma como se han ido apropiado de un recurso natural, como sería el oro.

Para los grupos mineros tradicionales, pequeños y medianos, así como sectores indígenas, la venta de las minas a la compañía minera significó "vender el pasado, el presente y el futuro... perder nuestra identidad, nuestro terruño, nuestras raíces... Yo me críe en esa mina, esa mina me dio todo, me ha dado todo lo que soy, la tranquilidad, mi familia" (líder minero, presidente Asociación de Mineros de Marmato y cofundador de Comité Cívico Prodefensa de Marmato, entrevistado por Eduardo Martínez Torres, 24 de abril de 2014, Marmato, Caldas).

Se puede decir que lo que estaba en juego en ese primer momento de contienda política dependía de las diferentes experiencias de cada sector, pero si se intenta comparar, poseen una significación semejante. Para ambos sectores mencionados, el objeto de disputa se ubicaba desde los espacios de vida (Ortiz, 1999; Orellana, 1999). En el sector indígena puede tener una conformación y un carácter más simbólico e inmaterial. El sector minero, resultado de los

7 Sandoval Robayo plantea el proceso alrededor de la minería de la siguiente forma: "470 años de explotación de oro de filón han estructurado una cultura amarrada a unas creencias y tradiciones, incidentes en el grado de racionalidad de las relaciones laborales, del trabajo y del comportamiento económico en general" (Sandoval, 2012, p. 146). sistemas productivos y materiales que se construyen desde el proceso minero de pequeña $y$ mediana escala, otorga a la minería fuertes elementos inmateriales y significación simbólica. Ambos sectores, mineros e indígenas, definen el objeto de lucha como medio y condición de la continuidad de la vida social y natural.

En Marmato, el proceso de simplificación de una experiencia de injusticia a uno de reacción, organización y movilización, cargada y condensada selectivamente de objetos, situaciones, acontecimientos, experiencias y secuencias de acciones $^{8}$ (Benford y Hunt, 1992) tuvo un fuerte origen y bagaje cultural, que fue altamente potenciado y (re)significado por las organizaciones locales. Es decir, este proceso de orientación se caracterizó por su anclaje en la ética popular de los grupos y la población agraviadas (Thompson, 1971), en torno a los espacios de vida (Ortiz, 1999), construidos desde los espacios de sociabilidad que crea la minería ancestral y tradicional.

Una primera estrategia, y la más relevante, es la de definir la minería en Marmato como un proceso que fue y ha sido fundamental en la historia de la nación colombiana.

\footnotetext{
Marmato está ligado a la historia de la nación. Durante la colonia, los españoles, con el trabajo de la población nativa, explotaron y saquearon las minas y, tras diezmar a los aborígenes, trajeron esclavos de África para continuar el saqueo del oro y la plata que enviaban a la metrópoli. Durante la guerra de independencia y la constitución de la República, Marmato contribuyó, con su riqueza, a la formación de lo que hoy es Colombia. Bolívar y los patriotas, para conseguir los recursos que permitieran pagar los créditos realizados para sostener la guerra de Independencia, comprometieron la riqueza
}

8 Una secuencia de valoraciones podría ser primero la forma ilegal en que la compañía minera adquiere títulos mineros en la parte alta del cerro, reservada por ley a la pequeña minería. Resultado de la compra de varias minas se deja sin trabajo a cerca de 850 trabajadores. El desprendimiento de tierra del 2006, usado por el gobierno y la compañía para justificar el traslado del pueblo. Esta sería una secuencia de los hechos injustos e intolerables identificados por los actores locales. 
aurífera con el gobierno inglés y pignoraron las minas. Durante muchos años, estas estuvieron arrendadas a los ingleses (Comunicado "No a la minería a cielo abierto en Marmato", junio, 2012).

Este fragmento establece un punto fundacional de Marmato, ligado a la minería desde la época de la Colonia, del papel que desempeñaron las poblaciones nativas y africanas en lo que las organizaciones llaman "el saqueo de oro y plata". Este punto fundacional de Marmato, como ícono de la identidad e historia colombiana, es (re)significado de igual forma en el papel, que jugó los recursos minerales del Cerro $\mathrm{El} \mathrm{Bu-}$ rro en los procesos de Independencia "Marmato contribuyó, con su riqueza a la formación de lo que hoy es Colombia". Si bien este proceso de orientación se caracterizó por su raigambre en una ética popular, en las experiencias locales de los procesos históricos de explotación de las poblaciones y de los recursos naturales, no es una selección que se haga de forma aleatoria o inconsciente.

\begin{abstract}
... Desarrollar un proyecto de minería a cielo abierto con lo que yo nunca estuve de acuerdo, porque eso implicaba la destrucción del pueblo como tal. Porque para desarrollar la minería a cielo abierto tenía prácticamente que desaparecer este pueblo, una reliquia histórica de la nación. Marmato es el cuarto pueblo más antiguo del país y por ende es el cuarto en historia (líder minero y comunitario, fundador del Comité Cívico Prodefensa de Marmato, 25 y 29 de abril de 2014, entrevistado por Eduardo Martínez Torres, Marmato, Caldas).
\end{abstract}

Esta fue una estrategia fundamental de los actores y organizaciones locales que buscan un reconocimiento de la lucha social y política, y la solidaridad de otros sectores más amplios de la sociedad colombiana. Llamaron la atención sobre lo que significa Marmato en la historia e identidad nacional y su importancia, que había sido olvidada, descuidada por grupos y sectores regionales de Caldas, por el conjunto amplio de la sociedad colombiana y la población local de Marmato. Importancia histórica (re)significada y activada en función de no permitir un proyecto de megaminería a cielo abierto.
Las ilegitimidades e ilegalidades no tolerables e identificadas por los actores y organizaciones locales terminaron transformándose en una defensa de la historia, la cultura y las tradiciones colombianas que son puestas en peligro por un agente externo, que es identificado como causante de atentar contra la tranquilidad, el trabajo y el territorio.

Esta orientación, realizada por los actores y organizaciones sociales, se articula con el elemento central de identificar causante(s) de la situación injusta e intolerable, y que atenta contra los espacios de vida (Orellana, 1999; Ortiz, 1999) de la población local. Esta identificación de los causantes y de la situación a trasformar, o más exactamente no permitir, está relacionada directamente con el encuentro de los actores y organizaciones locales con sectores como la academia, estudiantes y sindicatos. El encuentro y apoyo de estos sectores amplios, le otorga significaciones distintas al objeto de disputa. Lenguajes como compañías trasnacionales, agentes de capital extranjero, incursión de personas extrañas, no locales, ni nacionales, y que se traduce en saqueo de recursos naturales, y peor que por la incursión de unos extranjeros la población tuviera que emigrar para abrirles paso a ellos para sacar sus lucros económicos:

\footnotetext{
Si Marmato lleva 516 años de historia podríamos tener otros 10 o 20 siglos, mientras que si entra una trasnacional al municipio de Marmato, Caldas y adelanta un proyecto de minería a cielo abierto, máximo duraría 15 o 20 años, entonces la pregunta que nos hacemos es "¿qué va a pasar con mi descendencia?” (Líder minero y comunitario, fundador del Comité Cívico Prodefensa de Marmato, 25 y 29 de abril de 2014. Entrevistado por Eduardo Martínez Torres, Marmato, Caldas).
}

La contienda política en Marmato se condensó en una oposición de no permitir un proyecto a gran escala a cielo abierto, traduciéndose en no a las trasnacionales.

Las organizaciones y actores locales, al definir la trasnacional minera como agente causante de la situación, a las que es necesario oponerse, 
se entrelaza fuertemente con la importancia dada a Marmato en la historia e identidad nacional. Este ejercicio colectivo de orientación de carácter más amplio se torna más complejo, al elaborar una continuidad en los procesos de conquista, y los posteriores procesos de explotación y saqueo, por parte de los imperios coloniales sobre las comunidades afros e indígenas, $\mathrm{y}$, transponerlo en una continuidad histórica con los proyectos mineros a gran escala: "Nosotros somos descendientes de la etnia Caramanta, grupo Embera Chami. Somos ancestralmente un pueblo aurífero con 521 años de existencia... nosotros partimos de la ancestralidad, venimos siendo conquistados por las multinacionales" (exgobernadora y lideresa Cabildo Indígena Caramanta, 29 de abril de 2014, entrevistada por Eduardo Martínez Torres. Marmato, Caldas).

En otro momento de la contienda política, el objeto de disputa se fue trasformando en la medida que entran otros sectores y organizaciones, agregando otros elementos que ampliarán el volumen de la disputa, sumándole el lenguaje de defensa del medio ambiente y la naturaleza, o las promesas del desarrollo a través de la explotación de recursos naturales. Estrategias de los actores locales que buscan acentuar y 'adornar' la problemática social, de tal modo que al señalar agravios se pueda articular con otros lenguajes, construir colectivamente marcos de significación más amplios y que logren tener mayor receptividad y acogida por una parte más amplia de la sociedad -otorgándole mayor solidaridad- $u$ otros sectores que se sumen a la disputa. El proceso de orientación colectiva en el caso de Marmato en una fase consolidada de organización y movilización resultó condensándose y simplificándose bajo tres elementos principales: defensa del territorio, derecho al trabajo y control de recursos naturales.

Por último, se observan unas orientaciones gubernamentales sobre la población. Formas de sujeción, cuyo objetivo es la aceptación a los proyectos mineros de gran escala. Se apoyan en estrategias dirigidas a mantener y sujetar las conductas de una población amplia, que deben interpretar como razonables, propios y necesarios proyectos extractivos, a través de la vinculación con el progreso y desarrollo, vinculando eficaz y molecularmente la minería a gran escala con la vida social. De tal forma que se construya un modo de vida, una forma concreta de estar en el mundo, posibilitada y en función de políticas y racionalidad extractiva. Esto pasa no solo por una serie de proyectos ideológicos sino, sobre la producción de una serie de deseos, aspiraciones, creencias y sentidos sobre el mundo material y las relaciones humanas (Castro-Gómez, 2010).

Es necesario situar estos procesos de orientación gubernamental e institucional, como parte de estrategias en las que opera un complejo entramado de poder, y que configuran la contienda política sobre proyectos extractivos a gran escala. Estas orientaciones gubernamentales e institucionales buscan fomentar y favorecer el mantenimiento de ciertas relaciones asimétricas de poder político y económico. Buscan cualificar o descalificar sectores y organizaciones que se oponen abiertamente, y que se movilizan contra los proyectos de minería metálica a gran escala.

Lo que se define como orientaciones gubernamentales es una forma de vincular la minería a gran escala desde una 'regulación sensata', definida como una explotación de los recursos responsablemente y la preservación del ambiente. Estas orientaciones permiten construir unas condiciones de posibilidad, asociar la minería a gran escala con buenas prácticas y estándares internacionales, respeto a los derechos humanos y legislación laboral.

Estas estrategias se apuntalan en fuertes discursos desarrollistas; a través de la vinculación de proyectos mineros a gran escala y poblaciones, se sitúan como vía para salir del atraso, la pobreza, la marginalidad, al recurrir a figuras y objeto representativos, como es la "locomotora minera" de Santos, refiriéndose a los capitales privados mineros: "Este sector es un vehículo que recoge la riqueza del subsuelo y la trasforma" (presidente Juan Manuel Santos. III Congreso de Minería Responsable, 2014). La locomotora 
minera de Santos hace referencia a una metáfora, vehículo de industrialización de la Europa de los siglos XVIII y XIX y que si se usa y explota adecuadamente podría llevarnos a ese fin último que serían el 'progreso' y el 'desarrollo'.

Las orientaciones gubernamentales construyen e imaginan zonas y territorios definidos históricamente como marginales y pobres, en función de crear condiciones de posibilidad y aceptación local a este tipo de proyectos.

Las estrategias gubernamentales de orientación del gobierno de Santos explotan experiencias y condiciones (Brito, 2015) de miseria, pobreza y marginalidad que se pueden transformar con el aprovechamiento adecuado, responsable social y ambientalmente y, claro está, ubicar como único camino real y posible la explotación de los recursos mineros.

Por último, es necesario señalar que los procesos de orientación gubernamental producidos desde la centralidad buscan vincular y anudar lo macro y lo micro de las políticas mineras con discursos de disminución de la pobreza, diversificación productiva, una política pública con amplio carácter social y crecimiento económico. Estos lenguajes políticos no solo buscan expandirse y consolidarse a través de amplios aparatos de propaganda, sino profundizar localmente, hacer más relevante y significativa en la vida social el papel del gobierno y de las compañías mineras en los distintos aspectos de la vida local y sobre lo mas cotidiano de las comunidades. De tal forma que el poder central y el de la compañía sea visto no como una imposición, sino como un deseo, una necesidad que se pude disputar, contestar o resistir, pero de cualquier forma se reconoce y se acepta.

Pero la dinámica política no solo pasa por unos mecanismos que busquen seducir y atraer a las poblaciones locales, la dinámica de la contienda política tiene un componente fuerte de confrontación y de amenaza o uso de la violencia, como parte inherente de esta.

\section{A modo de conclusiones}

La forma como actores gubernamentales, privados y populares generan orientaciones más cercanas a las poblaciones, se acerquen y respondan más a sus necesidades, expectativas, deseos, o símbolos de desarrollo, básicamente produzcan sentidos de vida, facilita producir conductas dirigidas a crear, mantener o transformar relaciones asimétricas de poder en los conflictos y contiendas de proyectos extractivos.

Según se ha tratado de demostrar, la aceptabilidad de los proyectos mineros a gran escala en relación con poblaciones locales no se debe a que se haya logrado consolidar un poder "total", sino básicamente porque se producen unas condiciones de posibilidad, o se potencian unas existentes, buscando que sean acogidas por la gran mayoría, o una parte considerable de la población.

Esto no implica que actores y organizaciones sociales no se ubiquen en este plano, pero sí, como se ha señalado anteriormente, el manejo y la importancia otorgada por estos actores no institucionalizados está acompañado o atravesado por elementos simbólicos, no materiales, por lo que se ha denominado espacios de vida (Ortiz, 1999), sumado a los materiales y económicos. De esta forma, tanto organizaciones, actores sociales y populares como el gobierno central elaboran unas orientaciones que están dentro de una racionalidad estratégica y del enfrentamiento político y, al mismo tiempo, ubicados en un determinado contexto social y cultural que los posibilita y otorga mayores o menores efectos, significaciones y aceptabilidad social en función, y dependiendo, de lo que esté en juego.

La configuración del conflicto y de la contienda se caracterizó por su intensidad y energía invertida, que dependió fuertemente de lo que se estaría luchando para actores y organizaciones locales. Esta intensidad y energía invertida emergió desde las relaciones que se estructuraron alrededor y desde lo que estaría en disputa, que en un principio para actores y organizaciones locales serían las condiciones para mantener formas y espacios de vida. Fueron fundamentales los procesos colectivos de interpretación, (re)significación y apropiación que posibilitaron procesos organizativos y de movilización. Se constataron dos aspectos de 
la configuración del conflicto social: la relevancia de procesos de orientación en la construcción de un problema social a una confrontación abierta y pública, dos dimensiones de la contienda política, donde se vieron afectados grandes sectores de población. Segundo, las fases del conflicto, los cambios de actores y lo que se estaría luchando.

Por último, la intensidad y las formas como se exprese y desarrollen los conflictos sociales y para este caso, los conflictos socio-ambientales, los lenguajes y valoraciones, es decir, las orientaciones colectivas que resultan del conflicto mismo tienen una fuerte e intensa vinculación con la relación que ha tenido esa comunidad con los objetos de lucha. Es decir, mientras estos estén más arraigados en la cotidianidad y tengan fuertes lazos con los actores, el conflicto tenderá a ser más intenso, pero también deberá ser disputado por los distintos sectores que logren establecer acuerdos mínimos sobre cómo se orientan los distintos recursos materiales y simbólicos de una sociedad en una temporalidad especifica.

\section{Referencias}

Aguirre, C. A. (2010). Economía Moral de la Multitud. México D. F., México: UNAM.

Bebbington, A. (2009). Elementos para una ecología política de los movimientos sociales y el desarrollo territorial en zonas mineras. En A. Bebbington (Ed.), Minería, movimientos sociales y respuestas campesinas: una ecología política de transformaciones territoriales (pp. 23-46). Lima, Perú: IEP, CEPES.

Bebbington, A. (2013). Industrias extractivas, conflictos socioambientales y trasformaciones políticoeconómicas en América Latina. En A. Bebbington (Ed.), Industrias extractivas y dinámicas institucionales en la Región Andina (páginas). Lima, Perú: Instituto de Estudios peruanos, CEPES, Grupo Propuesta Ciudadana.

Benford, R. D. y Hunt, S. A. (1992). Dramaturgy and Social Movements: The Social Construction and Communication of Power. Sociological Inquiry, 62(1), 36-55.

Bottomore, T. (1975). Structure and History. En P. Blau (Ed.), Approaches 10 the Study of Social Structure (pp. 159-171). New York, US: Free Press.

Brito, J. M. (2015). La articulación del Movimiento Ecologista Canario (1989-1991): antecedentes, evolución y origen de la Federación Ecologista Canaria Ben Magec. Anuario de Estudios Atlánticos, (61), 1-19. Recuperado http://anuariosatlanticos.casadecolon.com/index.php/aea/article/view/9308

Cancino, A. (2012). La dudosa fortuna minera de Suramérica: los países andinos Colombia, Chile y Perú. En C. Toro, J. Fierro, S. Coronado y T. Roa (Eds.), Minería, territorio y conflicto en Colombia (pp. 59-78). Bogotá, Colombia: CENSAT- Agua Viva, Universidad Nacional de Colombia.

Castro-Gómez, S. (2010). Historia de la gubernamentalidad. Razón de Estado, liberalismo y neoliberalismo en Michel Foucault. Bogotá, Colombia: Siglo del Hombre Editores, Pontificia Universidad JaverianaInstituto Pensar, Universidad Santo Tomas.

Cisneros, P. (2007). Gobernanza ambiental y conservación de la naturaleza: un caso de control territorial indígena en el Parque Nacional Yasuní (tesis de Maestría). FLACSO-Ecuador, Quito, Ecuador.

Comité Pro Defensa de Marmato - Comité Ejecutivo del CRIDEC (2011, 22 de diciembre). Comunicado No a la Minería a Cielo Abierto en Marmato. Recuperado de http://censat.org/es/noticias/ concejo-municipal-de-marmato-detiene-la-explotacion-minera-a-cielo-abierto

Coser, L. (1961). Las funciones del conflicto social. Ciudad de México, México: Fondo de Cultura Económica. 
Dahrendorf, R. (1966). Sociedad y libertad. Hacia un análisis sociológico de la actualidad. Madrid, España: Editorial Tecnos.

Delgado, G. C. (2013). ¿Por qué es importante la ecología política? Nueva Sociedad, (244), 47-61.

Del Poso, R. (2010). Conflictos socio ambientales en las áreas de influencia del campo Libertador, provocados por la extracción petrolera de la filial Petroproducción en la región amazónica (tesis de maestría). FLACSOQuito, Quito, Ecuador.

Escobar, A. (2005). Más allá del Tercer Mundo. Globalización y diferencia. Bogotá, Colombia: Instituto Colombiano de Antropología e Historia.

Fontaine, G. (2006). Aportes a una sociología del conflicto socio-ambiental. Petróleo y desarrollo sostenible en Ecuador, 1, 79-102.

Galtung, J. (2003) Paz por medios pacíficos. Paz y conflicto, desarrollo y civilización. Bilbao, España: Gernika Gogoratuz.

Gamson, W. y Meyer, D. (1999). Marcos interpretativos de la oportunidad política. En D. Mc Adam, J. D. McCarthy y R. Zald (comps.), Movimientos Sociales: perspectivas comparadas (pp. 389-412). Madrid, España: Istmo.

Garvay, S. (2011). Desarrollo y Minería en el Ecuador: Un análisis del derecho de participación en el Proyecto Mirador (tesis de maestría). Universidad Andina Simón Bolívar, Quito, Ecuador.

Klandermans, P. B. (1998). A Movement Takes Office. En D. S. Meyer y S. Tarrow (Eds.), The social movement society: contentious politics for a new century (pp. 173-194). Lanham, USA: Rowman \& Littlefield.

Lefwich, A. (1987). Que es la política. Buenos Aires, Argentina: Fondo de Cultura Económica.

Lorenzo Cadarzo, P. L. (2001). Las principales teorías sobre el conflicto social. Norba, (15), 237-154.

Machado, H. (2011). El auge de la Minería transnacional en América Latina. De la ecología política del neoliberalismo a la anatomía política del colonialismo. En H. Alimonda (Coord.), La naturaleza colonizada. Ecología política y minería en América Latina (pp. 135-181). Buenos Aires, Argentina: CLACSO.

Martinez-Alier, J. (2004). Los conflictos ecológico-distributivos y los indicadores de sustentabilidad. Revibec: revista de la Red Iberoamericana de Economía Ecológica, 1, 21-30.

Mc Adam, D., Tarrow, S. y Tilly, C. (2005). Dinámica de la contienda política. Barcelona, España: Editorial Rustica.

Múnera, L. (1998). Rupturas y continuidades. Poder y movimiento popular en Colombia: 1968-1988. Bogotá, Colombia: IEPRI, Universidad Nacional de Colombia, CEREC.

Observatorio de Conflictos Mineros en América Latina OCMAL https://mapa.conflictosmineros.net/ ocmal_db-v2

Orellana, R. (1999). Aproximaciones a un marco teórico para la comprensión y el manejo de los conflictos socioambientales. En P. Ortiz-T (Comp.), Comunidades y conflictos soccioambientales: experiencias $y$ desafíos en América Latina (pp. 88-109). Quito, Ecuador: Ediciones UPS ABYA- YALA.

Ortiz, P. (1999). Apuntes teórico-conceptuales para el diseño de una propuesta metodológica de manejo de conflictos socioambientales a través de forestería comunitaria. En P. Ortiz-T (Comp.), Comunidades y 
conflictos socioambientales. Experiencias y desafíos en América Latina (pp. 7-32). Quito, Ecuador: Ediciones UPS ABYA- YALA.

Padilla, C. (2012). Minería y conflictos sociales en América Latina. En C. Toro, J. Fierro, S. Coronado y T. Roa (Eds.), Minería, territorio y conflicto en Colombia (pp. 37-58). Bogotá, Colombia: CENSAT-Agua Viva, Universidad Nacional de Colombia.

Ramírez, M. (2012). Territorialidad y conflicto en un contexto minero: el caso del municipio de Marmato, Caldas. Ánfora, 19(33), 89-113.

Rivas, A. (1998). El análisis de marcos: una metodología para el estudio de los movimientos sociales. En P. Ibarra y B. Tejerina (Eds.), Los movimientos sociales. Trasformaciones políticas y cambio cultural (pp 181218). Madrid, España: Trotta.

Romero, P. (2011). Minería, agroindustria y agricultura tradicional; conflictos socioambientales en el semiárido chileno, el caso de la comuna de Alto del Carmen. En H. Alimonda (Coord.), La Naturaleza colonizada. Ecología Política y minería en América Latina (pp. 285-293). Buenos Aires, Argentina: CLACSO, Ediciones CICCUS.

Sandoval, M. L. (2012). Habitus productivo y minería: El caso de Marmato. Universitas Humanística, (74), 145-172.

Santos, J. M. Palabras del Presidente en el Primer Congreso Anual de Minería a Gran Escala. Recuperado de https://www.youtube.com/watch?v=7um6rbWCQHA

Tarrow, S. (2004). El Poder en Movimiento: los Movimientos Sociales, la Acción colectiva y la Política. Madrid, España: Alianza.

Thompson, E. P. (1971). Costumbres en común. Barcelona, España: Critica-Grijalbo.

Toro, C. (2012). Introducción. Geopolítica energética: minería, territorio y resistencias sociales. En C. Toro, J. Fierro, S. Coronado y T. Roa (Eds.), Minería, territorio y conflicto en Colombia (pp. 17-36). Bogotá, Colombia: CENSAT- Agua Viva, Universidad Nacional de Colombia.

Triana, A. (Comp.). (2001). Nuevo Código de Minas (Ley 685 de 2001). Bogotá, Colombia: Leyer.

Vacaflorez, C. y Lizárraga, P.A. (2005). La lucha por el excedente del gas y la resignificación de las contradicciones de la identidad regional en Bolivia. Proyectos de dominación y resistencia en una región productora de hidrocarburos. Buenos Aires, Argentina: OSAL.

Wagner, L. S. y Goraud, M. (2011). El proyecto minero Potasio Rio Colorado: Conflicto Socioambiental, impactos regionales y falta de integralidad en la evaluación ambiental. En $\mathrm{H}$. Alimonda (Coord.), La Naturaleza colonizada. Ecología Política y minería en América Latina (pp. 261-288). Buenos Aires, Argentina: CLACSO, Ediciones CICCUS.

Wallerstein, I. (2001). Análisis del sistema mundo. Una introducción. Buenos Aires, Argentina: Siglo Veintiuno Editores.

Wright, C. (1994). La imaginación sociológica. México D. F., México: Fondo de Cultura Económica. 